\title{
Searchable Signatures: Context and the Struggle for Recognition
}

\section{ABSTRACT}

Social networking sites made possible through Web 2.0 allow for unique user-generated tags called "searchable signatures." These tags move beyond the descriptive and act as means for users to assert online individual and group identities. This paper presents a study of searchable signatures on the Instagram application, demonstrating that these types of tags are valuable not only because they allow for both individuals and groups to engage in what social theorist Axel Honneth calls the "struggle for recognition," but also because they provide contextual use data and sociohistorical information so important to the understanding of digital objects. Methods for the gathering and display of searchable signatures in digital library environments are also explored.

\section{INTRODUCTION}

A comparison of user-generated tags with metadata traditionally assigned to digital objects suggests that social network platforms provide an intersubjective space for what social theorist Axel Honneth has termed the "struggle for recognition." ${ }^{1}$ Social network users, through the creation of identity-based tags - or what can be understood as "searchable signatures"—are able to assert and perform online selves and are thus able to demand, or struggle for, recognition within a larger social framework. Baroncelli and Freitas cogently argue that Web 2.0, or the interactive online social arena, in fact functions as a "recognition market in which contemporary individuals ... trade personal worth through displays and exchanges of ... self-presentations." ${ }^{2}$

A comparison of a metadata schema used in Yale University's Digital Images Database with usergenerated tags accompanying shared photographs on the social networking platform Instagram demonstrates that searchable signatures are unique to social networking sites. As phenomena that allow for public presentations of disembodied selves, searchable signatures thus provide specific information about the context of the digital images with which they are associated. Capturing context remains a challenge for those working with digital collections, but searchable signatures allow viewers to derive valuable use data and sociohistorical information to better understand the world in which digital images originated and exist.

\section{LITERATURE REVIEW}

\section{Web 2.0 Identities and Recognition Theory}

While Web 2.0 can be imagined as a highly collaborative space where social actors are able to

Gina Schlesselman-Tarango (gina.schlesselman@du.edu) holds a Master of Social Sciences from the University of Colorado Denver and is currently an MLIS candidate at University of Colorado. 
communicate to the world new identities, some warn that this communication is somehow engineered and performed. Van Dijck, in an analysis of social media, argues that it is indeed "publicity strategies [that] mediate the norms for sociality and connectivity," and Baroncelli and Freitas note that Web 2.0 allows people to make themselves visible through modes of spectacularization. ${ }^{3}$

Though his focus is on the spectacle in fin de siècle France, Clark provides some insight into the effects of spectacularization on the individual. ${ }^{4}$ Working within a historical materialist framework, Clark points that with the growth of capitalism, the individual has become colonized. ${ }^{5}$ Clark further describes this colonization as "massive internal extension of the capitalist market-the invasion and restructuring of whole areas of free time, private life, leisure, and personal expression ... the making-into-commodities of whole areas of social practice which had once been referred to casually as everyday life." 6 Here, Web 2.0 is not a liberatory tool but instead a space where users are colonized to the extent that they create selves exchanged through social networking sites owned by capitalist enterprises. Web 2.0, then, has created a situation in which personal time and identification can be successfully commodified. Baroncelli and Freitas conclude, "From that formula, personal life becomes a capital to be shared with other people-preferably, with a large audience." 7 The problem, then, is that one's existence is defined simply "by being seen by others" and can no longer be understood as authentic. ${ }^{8}$

Despite the sophistication of the argument detailed above, there are some who view the online self, created through Web 2.0, as a legitimate and authentic identity. In an account of the online self, Hongladarom summarizes this position, noting that both offline and virtual identities are constructed in social environments. ${ }^{9}$ For Hongladarom, these identities are not different in essence because "what it is to be a person ... is constituted by external factors." 10 The online world as an external factor has the ability to affirm one's existence, regardless of whether that existence is physical or virtual. In sum, it is the social other and not a material existence that is the authenticating factor in identity formation.

There are others who validate the role that spectacle-or what also can be understood as performance-plays in identity formation. Pearson calls on the work of Goffman to argue, "identity-as-performance is seen as part of the flow of social interaction as individuals construct identity performances fitting their milieu." 11 For Pearson, the identity is always performed, be it through Web 2.0 or otherwise. There is nothing particularly worrisome, then, about the effects of Web 2.0 on the self, nor does Web 2.0 threaten the authenticity of the self. Identity is always performed and is in a sense a spectacle-this does not mean, however, that identity in itself is spurious.

It is with this perspective of the online self as a performed albeit authentic identity that this paper further develops. Before a thorough analysis of the searchable signature as an online self can be conducted, a deeper understanding of Honneth's theory of recognition is in order. 
In his 1995 work The Struggle for Recognition: The Moral Grammar of Social Conflicts, Honneth sets out to develop a social theory based on what he calls "morally motivated struggle." 12 Based on the Habermasian concept of communicative action, Honneth contends that it is through mutual recognition that "one can develop a practical relation-to-self [and can] view oneself from the normative perspective of one's partners in interaction, as their social addressee." 13 Relation-toself is key for Honneth, and he argues that a healthy relation-to-self, or what can be thought of as self-esteem, is developed when one is seen as valuable by others.

Beyond self-esteem, Honneth points that the success of social life itself depends on "symmetrical esteem between individualized (and autonomous) subjects." 14 For Honneth, this "symmetrical esteem" can lead to solidarity between individuals. "Relationships of this sort," he explains, "can be said to be cases of 'solidarity' because they inspire not just passive tolerance but felt concern for what is individual and particular about the other person." 15 That is to say that felt concern for another allows one to see the specific traits of the other as valuable in working towards common goals, and Honneth imagines that in situations of "symmetrical esteem ... every subject is free from being collectively denigrated, so that one is given the chance to experience oneself to be recognized, in light of one's own accomplishments and abilities, as valuable for society." 16 Until this ideal is realized, however, individuals must find sites in which to struggle to be recognized as valuable social assets.

According to Baroncelli and Freitas, it is in fact Web 2.0 that provides the arena where "the contemporary demand for the visibility of the self" is able to flourish. ${ }^{17}$ They position this argument within Honneth's framework, asserting that the visibility of self is "directed towards a quest for recognition," and they thus conclude that Web 2.0 can be understood as a "recognition market." 18

\section{Context and Its Importance}

Capturing and integrating markers of context into records, according to Chowdhury, still present a challenge for many. 19 "There is now a general consensus that the major challenge facing a digital library as well as a digital preservation program is that it must describe its content as well as the context sufficiently well to allow its correct interpretation by the current and future generations of users," he contends. ${ }^{20}$ Context in itself is difficult to define, let alone its myriad facets that might or might not facilitate better understanding of digital objects. Dervin, in her exploration of the meaning of context, points that it is often conceptualized as the "container in which the phenomenon resides." 21 She points that the list of factors that constitute the container and might be considered contextual is in fact "inexhaustible" - items on this list, for example, might include the gender, race, and ethnicity of those involved in a phenomenon. ${ }^{22}$ In an indexing or digital collection environment, the goal is to determine which of these many factors ought be included in a record to best allow for discovery and use. 
Others imagine context as a fluid, ever-changing process rather than as a static container of data. "In this framework," Dervin writes, "reality is in a continuous and always incomplete process of becoming." 23 This understanding of context as changing is helpful for those working with objects that live in digital environments, especially Web 2.0. Certainly the interactive nature of the web has created room for a variety of users to create, share, appropriate, comment on, tag, reject, celebrate, and ultimately understand images in a multitude of contexts that might be different from one moment to the next.

There are many reasons to include contextual information in records of digital objects. Lee argues that by providing context, or what he describes as the "social and documentary" world "in which [a digital object] is embedded," future users will be able to better understand the "details of our current lives." ${ }^{24}$ Further, Lee contends that context is helpful in that is illustrates the ways in which a digital object is related to other materials:

Relationships to other digital objects can dramatically affect the ways in which digitalobjects have been perceived and experienced. In order for a future user to make sense of a digital object, it could be useful for that user to know precisely what set of ... representations-e.g. titles, tags, captions, annotations, image thumbnails, video keyframes - were associated with a digital object at a given pointin time. ${ }^{25}$

The user-generated tag, then, is a valuable representation that provides contextual information surrounding the perception and experience of the image with which it is directly related.

\section{DISCUSSION}

\section{User-Generated Tags and Traditional Metadata}

User-generated tags have been hailed as an important stage in the evolution of image description and are said to have the potential to shape controlled vocabularies used in traditional metadata schemas. For example, in a comparison of Flickr tags and index terms from the University of St. Andrews Library Photographic Archive, Rorissa stresses the importance of exploring similarities and differences between indexers' and users' language, noting that "social tagging could serve as a platform on which to build future indexing systems." ${ }^{26}$ Like others, Rorissa hopes that continued research into user-generated social tags will be able to "bridge the semantic gap between indexerassigned terms and users' search language." ${ }^{27}$ In fact, some are currently utilizing social tags in an effort to describe and facilitate access to collections. One such organization is Steve: The Museum Social Tagging Project, "a place where you can help museums describe their collections by applying keywords, or tags, to objects." 28 The organization allows users to not only view traditional metadata associated with cultural objects, but also tags generated by others. In an effort to better understand the similarities and differences between user-generated tags and the language used in traditional metadata schemas, one must compare the two systems. 
Yale University's Digital Images Database provides a glimpse at the ways in which traditional metadata schemas are typically used to describe images in digital library settings. Most of the images included in the database are accompanied by descriptive, structural, and administrative metadata. For example, an item entitled "Boy sitting on a stoop holding a pole" (see figure 1) from the university's collection of 1957-90 Andrews St. George papers provides a digital copy of the image, the image number, name of the creator, date of creation, type of original material, dimensions, copyright information, manuscript group name and number, box and folder numbers, and a credit line. ${ }^{29}$ The image is further described by the following: "Man in the shed is making homemade bombs. The boy and man are also in image 45350." 30

\begin{tabular}{|l|l|}
\hline Title & Boy sitting on a stoop holding a pole. \\
\hline Image Number & 45351 \\
\hline Creator & Unknown \\
\hline Date of Creation & 1958 \\
\hline Original Material & Photographic prints \\
\hline Dimensions & $17.51 \times 24.56 \mathrm{~cm}$ \\
\hline Copyright Holder & $\begin{array}{l}\text { Copyright status for this item has been investigated but could } \\
\text { not be determined. }\end{array}$ \\
\hline Description & $\begin{array}{l}\text { Man in the shed is making homemade bombs. The boy and man } \\
\text { are also in image 45350. }\end{array}$ \\
\hline $\begin{array}{l}\text { Manuscript Group } \\
\text { Name }\end{array}$ & Andrew St. George papers, 1957-1990 (inclusive). \\
\hline Manuscript Group \\
Number
\end{tabular}

Figure 1. "Boy sitting on a stoop holding a pole" from Yale University's Digital Images Database collection of 1957-90 Andrews St. George papers, November 2012.

Certainly, such information is useful in library environments and provides users with helpful and formatted data to best guide the information discovery process. The finding aid for the Andrews St. George collection is additionally helpful in that it includes information about provenance, access, processing, associated materials, and the creator; it also contains descriptive information about the collection by box and folder number. ${ }^{31}$ However, if additional use data and sociohistorical 
information specific to this individual item were available, it would be most helpful in assisting users in determining the image's greater context. A study of modes of participation on social networking sites suggests that it is now possible to supply such contextual information for digital objects that live in interactive online environments.

A useful site for exploring user-generated tags associated with images is Instagram, a social application designed for iPhone and Android. ${ }^{32}$ Instagram users are able to upload and edit photos, and other users can then view, like, and comment on the shared photos. Instagram users are able to follow other users and search for photos by the creator's username or by accompanying tags. Instagram, owned by Facebook, is interoperable with other social networking sites, and users have the ability to share their photos on Facebook, Flickr, Tumblr, and Twitter. As of July 2012, it was reported that Instagram had 80 million users, and in September 2012, the New York Times reported that 5 billion photos were shared through the application. ${ }^{33}$

Users are limited to 30 tags per photo, and Instagram suggests that users be as specific as possible when describing an image with a tag so that communities of users with similar interests can form. ${ }^{34}$ Many tags, like the information included in traditional metadata schemas, aim to best describe an image by explaining its content; for example, one user assigned the tags \#kids, \#nieces, \#nephews, and \#family to a photograph of a group of smiling children (see figure 2). Like the information accompanying the photograph in the Yale University Digital Images Database, such tags provide users and viewers with tools to better determine the "aboutness" of the image at hand.

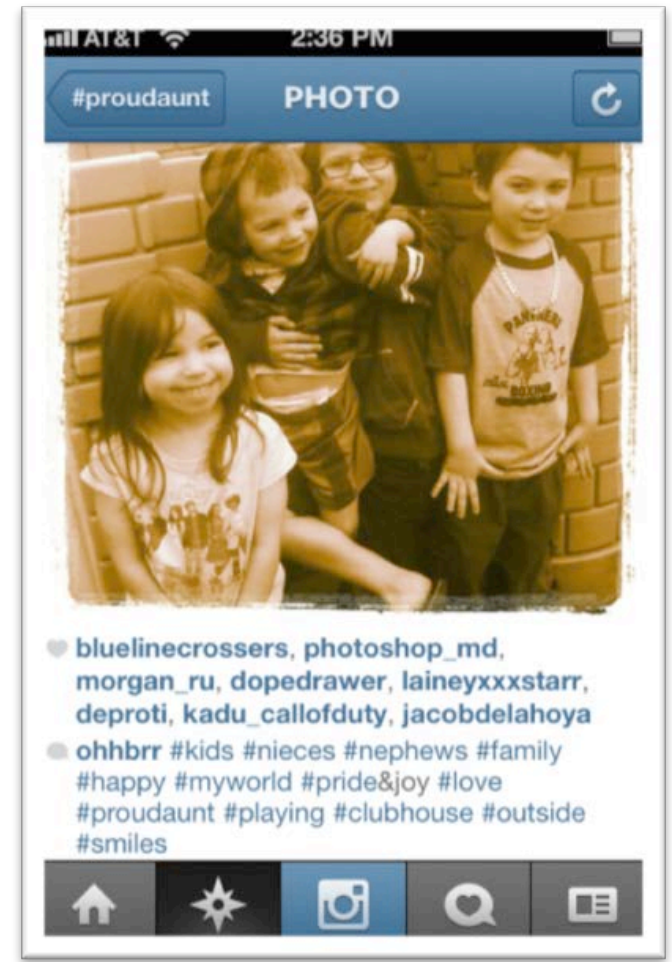


Figure 2. Photo shared on Instagram assigning both descriptive tags and the searchable signature \#proudaunt, November 2012.

However, Instagram users are repurposing the tagging function in a way that is unique to social networking sites. In addition to the descriptive tags assigned to the image of the children described above, the user also tagged the photo with the term \#proudaunt (see figure 2). There is, however, no aunt (what can be assumed to be an adult female) in the photograph. This tag, then, functions to further identify the user who created or shared the photograph and does not describe the content of the image at hand. A search of the same tag, \#proudaunt, demonstrates that this user is not alone in identifying as such: in November 2012, this search returned 40,202 images with the same tag and more than 58,000 images with tags derived from the same phrase (\#proudaunty, \#proudauntie, \#proudaunties, \#proudauntiemoment, and \#proudaunti) (see figure 3).

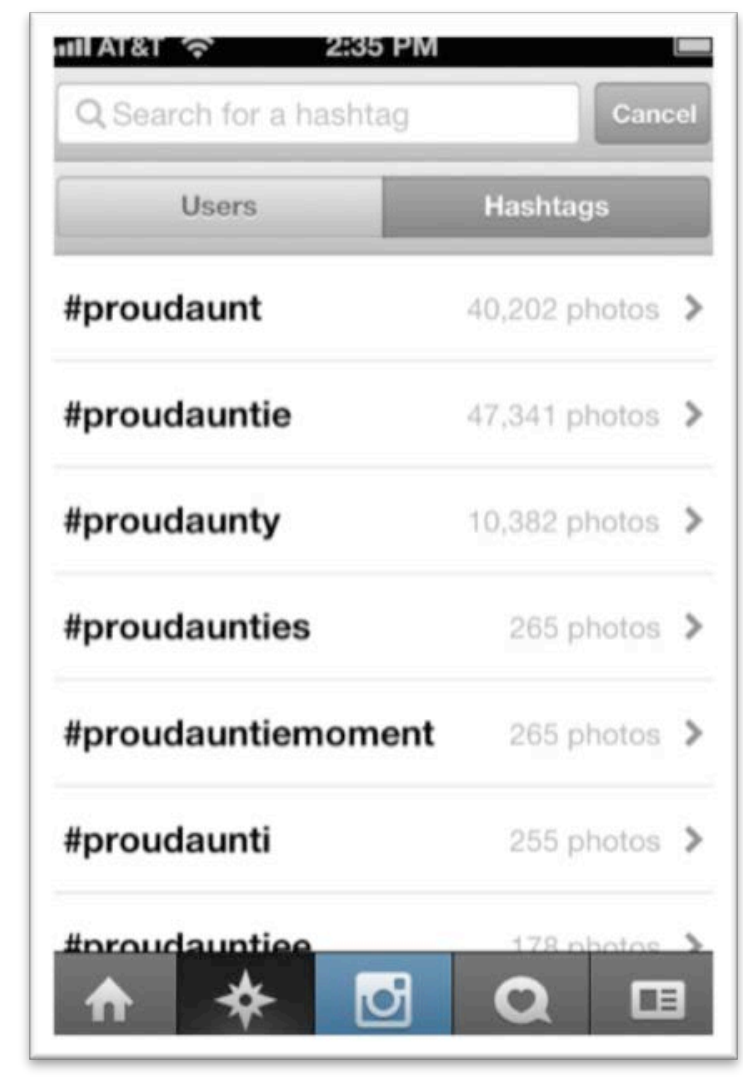

Figure 3. List of results from \#proudaunt hashtag search on Instagram, November 2012.

This type of user-generated tag-one that identifies the creator or sharer of the photograph yet is not necessarily meant to describe the content of the image-can be understood as a searchable signature. Such identity-based tags are not found within Yale University's Digital Images Database; the closest relative of the searchable signature is the creator's name. While searchable, this name is not alternative, or secondary, and it was not created and does not exist in a social environment. 
Currently, born-digital objects are often created and shared in a technological milieu that allows for the assignment of user-generated tags. Consequently, the integration of the searchable signature into the presentation of digital objects has become part of accepted social practice and offers unique opportunities for digital library curators and users alike.

Until quite recently, most materials-be they photographs, manuscripts, or government documents - were not born in digital environments. However, digitization projects have been undertaken to ensure that such historical materials are more widely and eternally available. These reborn digital objects, then, have been and can be integrated into dynamic social environments. Steve: The Museum Social Tagging Project, mentioned earlier in this paper, is one example of an organization that has capitalized on the social practice of user-generated tagging and is using descriptive tags along with traditional metadata to better describe reborn digital objects. It is important, then, to explore what (if any) implications the application of the searchable signature, a unique type of user-generated tag, has for historical objects that are later integrated into digital environments.

Searchable signatures associated with born digital images on social networking sites contain valuable information about their creators, users, and the images' context. One cannot ignore that users will, if given the chance, also likely apply signatures to reborn digital objects in similar ways that they do to objects that have always existed in social environments. Since the searchable signature is used to identify not only digital image creators, but also sharers, and if these signatures do in fact provide important insight into the sharers and their motivations, then these signatures are not to be ignored. Rather than focusing on the creating, the lens through which to understand the searchable signature for reborn digital objects can be shifted to the social act of sharing: by whom, when, in which social environments, and for what purposes. A deeper analysis of the presentation of self through the searchable signature and the role that the signature plays in providing valuable contextual information for both born- and reborn-digital objects is developed below.

\section{Searchable Signatures and the Struggle for Recognition}

If Web 2.0 indeed functions as a recognition market, then social media and social networking sites might appear to be tables at such a market. Placing oneself behind a table-be it Facebook, Twitter, or Instagram - the user is able to perform his or her online identity to passersby and effectively struggle to be recognized as a unique individual or as a member of a social group. These performances, which could be deemed narcissistic in nature, can alternatively be read as healthy attempts to self-actualize and connect to larger society. ${ }^{35}$ One such "table" in the recognition market is Instagram. Beyond Instagram's social nature that allows participants to interact with and follow one another, the specific role of the searchable signature is of interest to those who are concerned with struggles for recognition. Rather than describing shared images, searchable signatures reflect performative yet authentic user identities. 
McCune, in a case study of consumer production on Instagram, acknowledges the potential of the tag to not only facilitate image exchange but to communicate users' positions as members of social groups. ${ }^{36}$ Through a simple search of tags, users who identify as, for example, "cat ladies," are able to validate their identities when they see that there are many others who use the same or similar language in demonstrations of the self (see figure 4). Other signatures such as \#proudaunt, while not necessarily playful, still function to provide viewers with additional information about the Instagram user that cannot be determined through the photo itself. The ability to find images based on these searchable signatures allows users to find others who identify in a like manner and to imagine themselves as part of a larger social group. In effect, searchable signatures allow users to be recognized as social addressees of like-minded others. Positioning oneself within a group must be understood as a struggle for recognition, for to imagine oneself as part of the social fabric is also to see oneself as valuable.

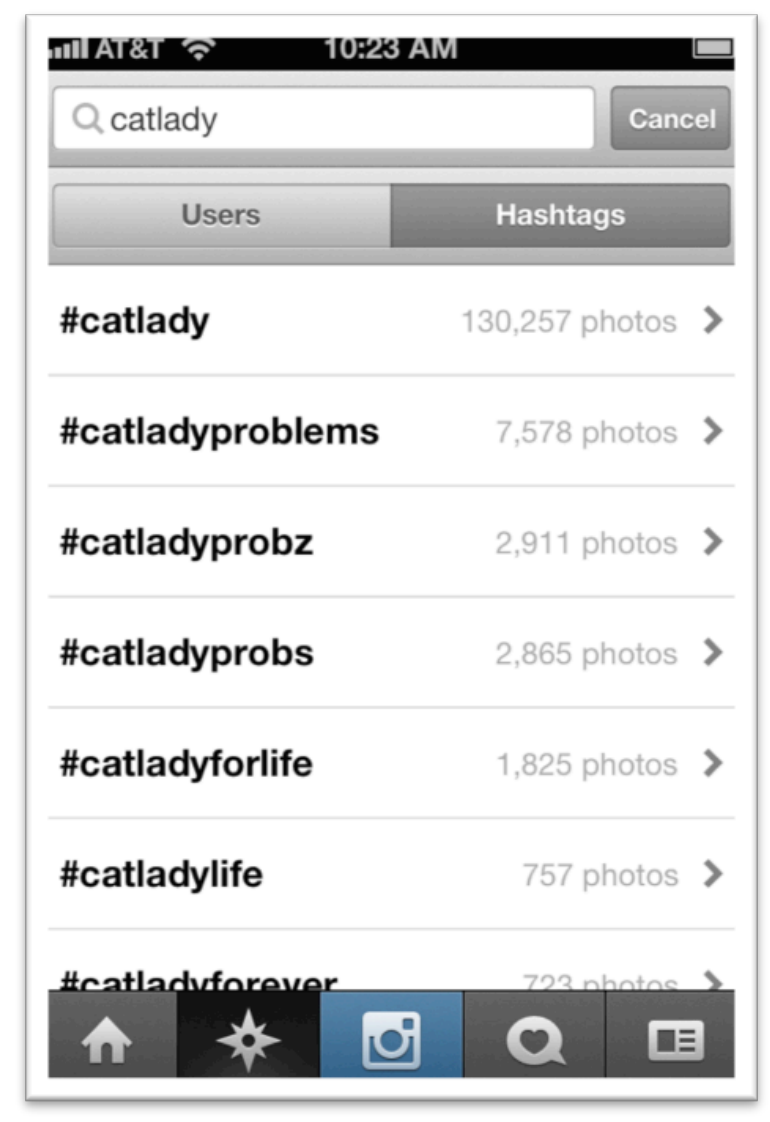

Figure 4. List of results from \#catlady hashtag search on Instagram, November 2012.

Enabled by Web 2.0, searchable signatures contain potential for marginalized peoples or groups to assert online selves to be seen and ultimately heard in a truly intersubjective landscape. It is not too much of a leap to imagine that searchable signatures might make possible the organization of individuals and groups for political purposes. In fact, in a discussion of social groups, Honneth notes that "the more successful social movements are at drawing the public sphere's attention to 
the neglected significance of the traits and abilities they collectively represent, the better their chances of raising the social worth, or indeed, the standing of their members." 37 Here, searchable signatures might provide such movements with a venue to capture the public's attention and to effectively struggle for and gain recognition.

\section{Searchable Signatures and Context}

As markers of individual and group identities, searchable signatures are unique in that they provide a snapshot of the multitude of social, historical, political, individual, and interpersonal relationships that ontologize the images with which they are paired. It is this very contextual information that is at times lacking in traditional indexing environments.

By examining searchable signatures, experts and users are able to understand which individuals and groups create, use, and identify with certain images. Thus, as markers of self, searchable signatures provide use data for scholars to better investigate which images are important to online individual or group identities. If the searchable signature is used in a political fashion, historians and sociologists might be able to study which types of images, for example, marginalized groups rally around, identify with, and use in their struggles for recognition.

Such use data also illuminates how and by whom certain digital images have been appropriated over time. For example, if a picture of a cat is first created or shared via Instagram by an animal rights activist, the image might be accompanied by the searchable signature \#humanforcats. This same image, shared by another user months later, might be accompanied by the \#catlady signature. Those interested will be able to examine how the same image has been historically used for different purposes and will be better able to grasp the evolving nature of its digital context.

In addition to use data, the searchable signature provides insight into the sociohistorical context surrounding digital images. For those who perceive "reality ... as accessible only (and always incompletely) in context, in specific historicized moments in time space" the searchable signature clarifies and makes more accessible that reality surrounding the digital image. ${ }^{38}$ In a traditional library setting, a photo of a cat might be indexed with descriptive subject headings such as "Cat," "Persian cat," or "Kitten-Behavior." However, the searchable signature \#catladyforlife provides additional information on how the cat has become, for a certain social group in a specific moment in time, a trope of sorts for those who are proud of not only their relationships with their domestic pets, but of their shared values and lifestyles as well. If a historian were to dig deeper, he or she also might see that "cat lady" has historically been used in a derogatory manner to mark single, unattractive women thought to be crazy and unable to care for the great number of cats they own and that, by (re)claiming this title, women might be engaging in a struggle for recognition that extends beyond mere admiration for felines. 39

Chowdhury, in a continued discussion of challenges facing the digital world, asks whether it is "possible to capture the changing context along with the content of each information resource, because as we know the use and importance... changes significantly with time." 40 Additionally, he 
asks, "Will it be possible to re-interpret the stored digital content in the light of the changing context and user community, and thereby re-inventing the importance and use of the stored objects?" 41 It is here that the searchable signature offers use data and sociohistorical information to illuminate the (changing) value digital images have for individuals, communities, and society.

\section{CONCLUSION}

Clark argues that representation must be understood within the confines of what he calls "social practice." 42 Social practice, among other things, can be understood as "the overlap and interference of representations; it is their rearrangement in use." 43 Representation of self also must be understood within current social practice, and an important facet of today's practice is Web 2.0.

As a social space, Web 2.0 allows for the creation of disembodied self-representations. One type of such representation, the searchable signature, is a phenomenon unique to social networking sites. While many acknowledge the potential of descriptive, user-generated tags to inform or even to be used in conjunction with metadata schemas or controlled vocabularies, Instagram users have created an additional, alternative use for the tag. Rather than simply using tags to describe shared images, they have successfully created a route to online identity formation and recognition. Searchable signatures demonstrate the power of the online self, as they allow users to struggle to be recognized as unique individuals or as parts of larger social groups. These signatures, too, might act as platforms on which social groups can assert their value and thus demand recognition.

Additionally, searchable signatures provide contextual information that reflects the social practice in which digital images live. While the capture and integration of such information remains a challenge for those engaged in traditional indexing, Web 2.0 allows for this unique type of usergenerated tag and thus provides better understanding of the context surrounding digital images.

As to the question of whether searchable signatures can be integrated into existing metadata schemas or be used to inform controlled vocabularies in library environments, it is not unreasonable to suggest that digital objects be accompanied by their supplemental yet valuable representations (e.g., searchable signatures and the like). Many methods exist through which these signatures might be both gathered and displayed. Certainly, a full exploration of such practices is the stuff of future research; however, some initial ideas are detailed below.

One method of gathering identity-based tags would involve the active hunting down of searchable signatures. Locating objects on social networking sites that are also in one's digital collection, the indexer would identify and track associated user-generated searchable signatures. This method would require extreme diligence, high levels of comfort navigating and using Web 2.0, a clear idea of which social networking sites yield the most valuable searchable signatures, and likely one or more full-time staff members devoted to such activities. Even if feed systems were employed for individual digital objects, this method demands much of indexers and would likely not be sustainable over time. 
A more passive yet efficient way of gathering searchable signatures would simply be to build on methods that have shown to be successful. By creating interactive digital environments that encourage users to assign not only descriptive but also identity-based tags, indexers are freed of the time-consuming task of hunting for searchable signatures on the web. Since searchable signatures have come to be part of online social practice, the assigning of them would likely be familiar to users-initially, libraries might need to prompt users to share signatures or provide them with examples. This gathering tactic could be used to harvest signatures for items that are already part of the library's digital collection (telling us about signatures used by potential sharers) or as a means to incorporate new digital objects into the collection (telling us about signatures used by both creators and sharers). In both gathering scenarios, indexers might choose to display only the most occurring or what they deem to be the most relevant searchable signatures, or they might choose to display all such tags; decisions such as these will ultimately depend on each institution's mission and resources.

Of course, if a library integrates a born-digital image into its collection and can identify the searchable signatures originally assigned to it via social networking sites or otherwise, this information should also be recorded. Here, users will be able to get a glimpse of the image in its pre-library life. Providing associated usernames, dates posted, and the name of the social networking sites too will assist in providing a more complete picture of the individuals or groups linked to the image. This information can provide valuable data about the information creators and sharers who use specific social platforms.

The aim of this paper is to lay the theoretical groundwork to better understand the role of searchable signatures in today's digital environment as well as the signature's unique ability to provide context for digital images. Surely, further research into the phenomenon of the searchable signature would demonstrate how it is currently used outside of Instagram or as a political tool. Others might consider examining the username as another arena in which individuals or groups construct and perform online identities and thus engage in struggles for recognition. Usernames also might provide contextual use data and sociohistorical information that inevitably support greater understanding of digital objects. Finally, further research is needed to identify how libraries could utilize the searchable signature in promotional activities and to build and cater to user communities.

\section{REFERENCES}

1. Axel Honneth, The Struggle for Recognition: The Moral Grammar of Social Conflicts (Cambridge: MIT Press, 1995).

2. Lauane Baroncelli and Andre Freitas, "The Visibility of the Self on the Web: A Struggle for Recognition," In Proceedings of 3rd ACM International Conference on Web Science, 2011, accessed August 12, 2013, www.websci11.org/fileadmin/websci/Posters/191 paper.pdf. 
3. Jose van Dijck, "Facebook as a Tool for Producing Sociality and Connectivity," Television \& New Media 13, no. 2 (2012): 160-76; Baroncelli and Freitas, "The Visibility of the Self."

4. T. J. Clark, introduction to The Painting of Modern Life: Paris in the Art of Manet and His Followers (Princeton, NJ: Princeton University Press, 1984), 1-22.

5. Ibid.

6. Ibid., 9 .

7. Baroncelli and Freitas, "The Visibility of the Self."

8. Ibid.

9. Soraj Hongladarom, "Personal Identity and the Self in the Online and Offline World," Minds \& Machines 21 (2011): 533-48.

10. Ibid., 541.

11. Erika Pearson, "All the World Wide Web's a Stage: The Performance of Identity in Online Social Networks," First Monday 14 (2009), accessed November 9, 2012, www.uic.edu/htbin/cgiwrap/bin/ojs/index.php/fm; Erving Goffman, The Presentation of Self in Everyday Life (Garden City, NY: Doubleday, 1959).

12. Honneth, The Struggle for Recognition, 1.

13. Jurgen Habermas, The Theory of Communicative Action (Boston: Beacon, 1984); Honneth, The Struggle for Recognition, 92.

14. Honneth, The Struggle for Recognition, 129.

15. Ibid.

16. Ibid., 130.

17. Baroncelli and Freitas, "The Visibility of the Self."

18. Ibid.

19. Gobinda Chowdhury, "From Digital Libraries to Digital Preservation Research: The Importance of Users and Context," Journal of Documentation 66, no. 2 (2010): 207-23, doi: 10.1108/00220411011023625.

20. Ibid., 217.

21. Brenda Dervin, "Given a Context by Any Other Name: Methodological Tools For Taming the Unruly Beast," in Information Seeking in Context, ed. Pertti Vakkari et al. (London: Taylor Graham, 1997), 13-38. 
22. Ibid., 15.

23. Ibid., 18.

24. Christopher A. (Cal) Lee, "A Framework for Contextual Information in Digital Collections," Journal of Documentation 67 (2011): 95-143.

25. Ibid., 100.

26. Abebe Rorissa, "A Comparative Study of Flickr Tags and Index Terms in a General Image Collection," Journal of the American Society for Information Science and Technology 61, no. 11 (2010): 2230-42.

27. Ibid., 2239.

28. "Steve Central: Social Tagging for Cultural Collections," Steve: The Museum Social Tagging Project, accessed December 16, 2012, http://tagger.steve.museum.

29. "Yale University Library Manuscripts \& Archives Department," Yale University Manuscripts \& Archives Digital Images Database, last modified April 19, 2012, accessed December 3, 2012, http://images.library.yale.edu/madid.

30. Ibid.

31. “Andrew St. George Papers (MS 1912)," Manuscripts and Archives, Yale University Library, accessed April 30, 2013, http://drs.library.yale.edu:8083/fedoragsearch/rest.

32. "FAQ" Instagram, accessed November 10, 2012, http://instagram.com/about/faq.

33. Emil Protalinksi, "Instagram Passes 80 Million Users," CNET, July 6, 2012, accessed November 13, 2012, http://news.cnet.com/8301-1023 3-57480931-93/instagram-passes-80-millionusers; Jenna Wortham, “It's Official: Facebook Closes Its Acquisition of Instagram,” New York Times, September 6, 2012, accessed November 13, 2012, http://bits.blogs.nytimes.com/2012/09/06/its-official-facebook-closes-its-acquisition-ofinstagram.

34. “Tagging Your Photos Using \#hashtags," Instagram, accessed November 10, 2012, http://help.instagram.com/customer/portal/articles/95731-tagging-your-photos-usinghashtags; "Instagram Tips: Using Hashtags," Instagram, accessed November 10, 2012, http://blog.instagram.com/post/17674993957/instagram-tips-using-hashtags.

35. Andrew L. Mendelson and Zizi Papacharissi, "Look at Us: Collective Narcissism in College Student Facebook Photo Galleries," in A Networked Self: Identity, Community and Culture on Social Network Sites, ed. Zizi Papacharissi (New York: Routledge, 2010), 251-73.

36. Zachary McCune, “Consumer Production in Social Media Networks: A Case Study of the 
'Instagram' iPhone App" (master's dissertation, University of Cambridge, 2011), accessed December 20, 2012, http://thames2thayer.com/portfolio/a-study-of-instagram.

37. Honneth, The Struggle for Recognition, 127.

38. Dervin, “Given a Context by Any Other Name," 17.

39. Kiri Blakeley, “Crazy Cat Ladies,” Forbes, October 15, 2009, accessed December 4, 2012, www.forbes.com/2009/10/14/crazy-cat-lady-pets-stereotype-forbes-woman-time-

felines.html; Crazy Cat Ladies Society \& Gentlemen's Auxiliary homepage, accessed December 4, 2012, www.crazycatladies.org.

40. Chowdhury, “From Digital Libraries to Digital Preservation,” 219.

41. Ibid.

42. Clark, introduction to The Painting of Modern Life, 6.

43. Ibid.

\section{ACKNOWLEDGMENTS}

Many thanks to Erin Meyer and Dr. Krystyna Matusiak at the University of Denver for their feedback and guidance. 